\section{Anthony Bagshaw} is managing director of Gecko Direct, a marketing services agency that helps clients to acquire, develop and keep more customers through relevant, targeted communications.
Keywords: direct mail, marketing automation, marketing ROI

\section{Accelerating lead development}

\section{Automation is misleading term}

\section{Strategic planning is vital}

\section{Test and learn}

Anthony Bagshaw Fairbank House, Moorfield Business Park, Moorfield Close Yeadon, Leeds, LS19 7YA, UK

Tel: 01133910704

E-mail: a.bagshaw@gecko.co.uk

\section{Opinion Piece}

\section{What is marketing automation?}

\section{Anthony Bagshaw}

Received (in revised form): 28th September 2015

\author{
Abstract \\ This article looks at how brands can incorporate direct mail into \\ automated marketing programmes and the benefits this channel can \\ yield for businesses. \\ Journal of Direct, Data and Digital Marketing Practice (2015) 17, 84-85. \\ doi:10.1057/dddmp.2015.46
}

Aside from being the latest buzzword, in simple terms marketing automation is the use of software to automate marketing processes, such as customer segmentation, customer data integration and campaign management. Implemented correctly, the right marketing automation solution helps you focus on your customers and accelerate buyers through your sales funnel, with far less human resource and at much lower costs. The use of automation software can help you centralise your data, deliver a far more relevant (and complex) contact strategy, nurture leads into potential customers and make it easier for you to track the success of your marketing campaigns.

If that's the case, automating your marketing sounds like a no-brainer, doesn't it? Especially if it saves central resource lots of time and hassle getting campaigns out and sales in? So, why haven't all companies achieved results with automation? Firstly, the word automation can be misleading. It does not mean that you sit back and let technology do all the work.

A brand needs a strategic plan and must be able to adapt its marketing activity and campaigns based on results. Those businesses that have failed to realize the potential in automation are those that have not planned every aspect of their campaign or customer journey to ensure they reach people at the right time with relevant propositions. Without this planning, automation quickly becomes a waste of time, money and resource.

Technology gives marketers options, but before investing in automation, set measurable objectives, understand your customer data and behaviour, and be willing to test and learn, adapt and test again! In addition, there's more to automation than online. It's too easily dismissed as a tool with which to spam your customers with emails. Simply blasting an up-sell email to customers who have just purchased from you when the average frequency of purchase is high means they'll become disengaged from your brand very quickly, when a simple thank-you message would have been appropriate. 
Direct mail drives sales

Digital print costs
falling

Relevant, targeted, timely
The biggest marketing automation companies in the market claim to be automating campaigns across all channels. When you actually look into it, by 'all channels' they actually mean all online channels - no direct mail in sight. Why would traditional automation not include this vital part of the marketing mix, particularly when Royal Mail's recent study into the 'Private life of mail' found that multi-media campaigns that included mail were 27 per cent more likely to deliver top-ranking sales performance and 40 per cent more likely to deliver top-ranking acquisition levels than campaigns that didn't include mail.

Digital print technology is now so flexible and responsive that direct mail has a fully deserved place back in the channel mix. The surge in direct mail usage continues, with Royal Mail reporting that digitally printed (ie, relevant and targeted) direct mail costs have fallen by 25 per cent over the past five years. Yet, on the whole, marketing automation programmes seem to be ignoring this channel.

Today's consumer is more astute. We know more about their preferences than ever before and we know that communicating across different channels delivers results. The key to the success of marketing automation is understanding these preferences, spotting relevant communication triggers and converting these into relevant, targeted and timely messages that drive more profitable customer behaviour. 